\title{
Pharmaceutical Companies: A Study of their Operation and Regulatory Mechanism in India
}

\author{
Meenu Sharma and Sachin Rastogi \\ Amity Institute of Advance Legal Studies, Noida, India
}

\section{ABSTRACT}

The Research topic under the caption aims at its own essence especially dealing with Pharmaceutical Companies, their products and operation within the Indian territories whether as Foreign Company and/or Indigent incorporated legal entity. A general ascertainment of such companies places them at a figure more than 10563 as up to 2020 out of total active companies including other than pharma companies in India standing at 1,19,5045.The Pharmaceutical Companies are located in different Indian state with highest number in Maharashtra being 3139 .Most of the states do not show the presence of said companies in their geographical areas . In India the top of the Pharmaceutical Companies still are non-indigent like Johnson and Johnson with 56.1 bn US\$, Pfizer with 51.75bn US\$, Roche at 49.23 bn US\$, Novartis with 47.45 bn US $\$$ and at fifth one finds Merch \&Co having 46.84bn US\$ as capital adequacy . All these companies in addition to other Regulatory Mechanism fall within the Regulatory mechanism of Indian laws including that provided under the Companies Act as far the Incorporation is concerned and for manufacturing, sale and like other activities they come under the Drugs and Pharmaceutical Companies Act,1940.The Regulatory system covers the compliances for various laws including those under respective States where the Pharmaceutical Company(s) is Registered, established and/or operating in a way India reflects multiple Regulators with divergent approach. The analysis and deliberations are based on doctrinal methodology based on both primary and secondary source of data for answer to Research question with respect to diverse Regulatory mechanism and its effectiveness in achieving the objective.

KEY WORDS: PHARMACEUTICAL, COMPANIES, REGULATIONS, COMPLIANCES, DRUGS , DOMESTIC MARKET , TURN OVER, INDIGENOUS COMPANIES

\section{INTRODUCTION}

The pharmaceutical companies are not different from others sector companies as per as legalities and procedures there to for incorporation are concerned. A pharmaceutical like other companies ought to get themselves Registered under the Companies Act and/or like law to become an incorporated entity capable to sue and be sued. The members of the such company are separate and distinct from the corporation as a jurists person .Though this is the case, but the objective of the company being of special nature to carry on the activities of pharmacy including the drug manufacturing, patenting there to, besides others. In this way ,once company comes into being as a legal entity

Biosc Biotech Res Comm P-ISSN: 0974-6455 E-ISSN: 2321-4007

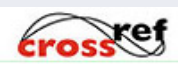

Identifiers and Pagination

Year: 2021 Vol: 14 No (9) Special Issue

Pages: $87-90$

This is an open access article under Creative

Commons License Attribn 4.0 Intl (CC-BY). DOI: $h t t p: / / d x$.doi.org/10.21786/bbrc/14.9.19 but for carrying out its object of drug manufacturing, they have to approach the controller whether State or Centre or both for obtaining licence to manufacture and for other allied activities .The pharmaceutical industry comprising of Companies /Corporations have number of unusual characteristics that make them very different from what people normally think of as an industry.

It is an industry replete with contradictions while contributing to human wellbeing and the reduction of ill health at the cost and consideration. As such it is undoubtedly considered as one of the riskiest businesses in which to invest money as being perceived to be excessively profitable. The major pharma companies rightly promote themselves as being research-based organizations yet top five pharma companies in India are non-indigenous like Johnson and Johnson with 56.1 bn US\$, Pfizer with 51.75bn US\$, Roche at $49.23 \mathrm{bn}$ US\$, Novartis with 47.45 bn US\$ and at fifth one finds Merch \&Co having 46.84bn US\$ as capital adequacy. Indian Manufacturing Companies are also in race and respectability.

\section{Article Information}

Received: $10^{\text {th }}$ May 2021 Accepted after revision: $05^{\text {th }}$ July 2021 
The objective of the Research paper is to provide a backdrop to the business so that the challenges of the issue of pharmaceuticals in the environment can be better understood especially in multidimensional Regulatory Mechanism. One need to note that the words "medicine," "pharmaceutical" and "drug" are often used interchangeably and the word "drug" can also mean both a medicine and an illegal substance, depending on the context. The word "pharmaceutical" is deliberately assigned to the end-products of the pharmaceutical industry, the product where are is used by patients, medical professionals and hospitals saleable and exhibited at different pharma outlets. The word "drug" so far mentioned is mainly used for potential pharmaceuticals which is one of the world's most research-intensive industries, generating a continuing steam of new products that save lives and raise the quality of life. The safety and efficacy of new pharmaceutical products are stringently regulated in most industrialized nations, adding to clinical testing costs.

Constitutional Mandate $\&$ pharmaceutical companies: India is a Constitutional Governance Sovereign State. The governance and law making derives its power from the Constitution which stands as a ground norm.1 Nobody shall be deprived of his life and personal liberty except the procedure established by law when read with directive principles like the state shall endeavor among others 'Child Care',2 besides the duty is imposed on State to raise the level of nutrition and standard of living and to improve public health.3 For Law making on pharmaceuticals including Drugs same falls under the concurrent list of the constitution giving power to both state and Centre to make the laws on 'Drugs and poisons, subject to provisions of entry 59 of List -I with respect to opium. The entry before that in concurrent list gives power to make laws for Adulteration of foodstuffs and other goods.

Pharmaceutical companies and Policies for Guidance: India in its post-independence laid emphasis on Agriculture and Industry as national policy. The Industries Act, 1949 is an indicator for industrialization especially manufacturing industries with substantial net worth. Other legislations also assumed importance like the Companies Law as an entity for manufacture. The creation of legal entity, as a juristic person made things easy for manufacture of pharmaceuticals which include drugs. But even after creation of a legal entity , it became imperative to provide a Regulatory mechanism for licensing, inspection and monitoring the manufacture of drugs with standards and genuineness.

In this the Pharmaceutical Companies emerged though as ordinary companies with an object of drug manufacturing, sale and marketing of manufacture of drug as remedy for disease or otherwise. At the same one sees the import of drugs in India as indigenous products with marketing and operation within the Indian territories whether as Foreign Company and/ Indigent incorporated legal entity for the purpose. The quantum of such companies as up to 2020 is estimated at more than 10563 out of total active companies in India including pharma companies standing at 1,19,5045. The Domestic Market Turnout of manufacturing Pharma units/companies itself is increasing which reached 20.03 bn US \$ in 2019. There was upward trend of 9.3bn US\$ from the then figure of 2018 .The Pharmaceutical Companies are located in different Indian state with highest number of 3139 being in Maharashtra.5 In this way one arrives at a finding that there is an expansion of indigenous Pharmaceutical companies from decade to decade. Side by side foreign pharmaceutical companies are also operating with Indian offshore office and/or manufacturing unit including as operating Transnational Company (TNC's /Multinational Company (MNC's) as the case may be.

Regulatory Mechanism in relation to Drug Manufacturing: For manufacturing the drugs whether in relation to Allopathic or Ayurvedic, a license is needed before carrying any such manufacturing activity. The Licensing Authority is provided under the Drugs and Cosmetics Act ,1940 amended from time to time to cover the changing scenario and time to time developments. The Licensing Authority is at State and Central Level. The State licensing Authority has its role with respect to manufacturing units operating within the state. The State level Authority has a power not only to issue license but also to monitor drug manufacturing, which is imperative on them by adhering to regular inspections of manufacturing units , sale premises to prevent abuse and other malpractices inter-alia by enforcing the Food and Drug laws.

For manufacturing of drugs / pharmaceuticals the mandatory function of the inspection and office work is to recommend and issue manufacturing licenses under the referred statutes and rules thereto. Towards this an Application for availing License under drugs and cosmetic Act, 1940 is filed before the state authority or under the referred Act which is entrusted to senior Inspector for inspecting the premises etc. and for submission of report. On the strength of report when received either the license is granted, or the Application filed for grant of license is rejected. The license may specify other additional items only after due scrutiny. It is also perceived that for testing Laboratories to carry out the test/analysis on behalf of manufacturers, a procedure of joint inspection is carried out by the State Authority and the central Drug Inspectors.

Other Compliances: As already deliberated that in India, the Regulatory Mechanism with respect to manufacturing pharmaceuticals companies is multifarious which for understanding can be categorized into two broader areas like i) Core Regulatory Mechanism; and ii) NonCore Mechanism. The Core Regulatory Mechanism has been dealt herein before while the Non-Core Regulatory Mechanism commences from the very beginning of creation as company/corporation and/or otherwise as may thought as a proper entity for carrying the manufacturing of drug activity. Once a legal entity is constituted, it is followed by infrastructure including land and building for which different Regulator manages the affairs that of Development Authority within the 
Metros and Cities, while for Semi-Urban and Rural the Revenue and Panchayats rules/procedures are to be followed in presence of Regulator for Drugs under the Drug and cosmetics Act, 1940 modified from time to time7 with Notification of 2020 for effective compliance. In some circumstances, compliances under the Shop and Establishment Laws of respective state may also get attracted. This apart for manpower management, the labor laws like Equal Remuneration Act, 1976 Payment of wages Act, 1936, besides others may have to be followed. The other Regulations mentioned though not Core Regulatory Mechanism still retain fringe aspects for ancillary compliance. The Compliance and Regulatory Mechanism stands diversified with core issues Under the Drug policy and the Statute(s) thereto.

Judicial Adjudication and Sanctions: In the context referred above number of cases have come for judicial adjudication for which selected few are dealt and deliberated. In Swantraj V. State of Maharashtra,9 the judgement deals with manufacture, stock, and sale of drugs. The judgement of the Bombay High Court in no uncertain terms observes that that no person shall manufacture for sale, or sell, or stock or exhibit for sale or distribute any drug except under a licence and s. 27(b) provides for punishment for its contravention. Similarly, in Southern Pharmaceuticals \&t Chemicals ,Trichur and others V. State of Kerala, 10 where the Appellants were manufacturers of medicinal and toilet preparations containing alcohol, challenged the Constitutional Validity provisions 12-A ,12 -B, 14-e and f , 56 -A and section 68 -A of Kerala Abkari Act ,1967 in their writ petition under Article 226 of the Constitution of India. The legislation and Regulatory actions were subject matter of the cases also like in Vincent Panikurlangara V. Union of India \& others11 where the petitioner, an advocate by profession moved the Supreme Court in public interest seeking directions banning import, manufacture, sale and distribution of such drugs which have been banned in Western countries or recommended to be banned by the Drugs Consultative Committee under the respective laws thereto.

The Judicial approach has been conducive and curative as it has expanded the Powers of the Central Government under section 26-A of the Drugs Act thereby enabling the Central Government to prohibit the use and manufacture of any drug without the consultation of the DTAB12 or any other Committee provided the parameters of section 26-A of the Drugs Act are met. Although the fate of FDC's which have been referred to DTAB is still to be decided, the pharmaceutical companies can manufacture and sell those FDC's till the Central Government issues appropriate Notifications after receiving the recommendation s of DTAB. The fate of pre 21 September ,1988 FDC's which were approved by DCG(I) is not yet clear. In short, the Supreme Court has preserved the right of Central Government to carry out an inquiry as to whether such drugs should be the subject matter of a notification under section 26-Aof the Drugs Act.

\section{CONCLUSION AND SUGGESTIONS}

The deliberations afore mentioned on 'Pharmaceutical Companies: A Study of their Operation and Regulatory Mechanism in India' leads to believe that the pharma sector is distinct in its own nature with base being in the Companies Act ,2013 at present. However, for carrying the objective of manufacturing drugs and other related commodity the approval from Regulator is warranted in the form of license with such conditions as may be deemed appropriate. The Pharmaceutical Manufacturing Companies is subject to periodical inspections by the drug controller through its inspectors. Other than Core Regulator, the ancillary Regulators towards infrastructure, labor, technician, and others have also monitoring role but confined to their respective areas . The State and Centre Licensing authority have onerous obligations as the manufacturing is concerning physical health, care for maintenance of standards Constitution carves out obligations and government has state responsibility for any wrong and/or deviation even as reflected in referred case deliberated hereinbefore. In the process it is expected that there ought to be strong and credible Regulatory Mechanism for which the identification of experts is required with sincerity, zeal and clarity about law and health hazards. The Industry requires a cross check to ascertain the proper functioning of controllers. All this will necessitate internal as well as external monitoring. The grant of License or refusal thereto needs urgent disposals. The adjudication of cases concerning Drug manufacture violation ought to be dealt expeditiously by the present dispensation. In alternative special Tribunals ought to be entrusted for dispensation of violation and cases where cause of action arises.

Ethical clearance: The approval of Institutional Ethics Committee is not required as the research does not involve any in-vivo study.

Source of funding: From own resources.

Conflict of Interest: Meenu Sharma and Prof. Dr. Sachin Rastogi declare that they have no conflict of interest.

\section{REFERENCES}

Ahmed F. (2014) An alternative model of health delivery system to improve public health in India. Indian journal of public health. Oct 1;58(4):261.

Bhurosy T, Jeewon R. (2014) Overweight and obesity epidemic in developing countries: a problem with diet, physical activity, or socioeconomic status? The Scientific World Journal. Oct;2014.

Chak D. (2007) Affirmative Action in Indian Higher Education: Myths and Realities. NALSAR Stud. L. Rev. ; 3:1.

Das JK. (2011) Investigation Techniques in Criminal Cases and the Right to Health in India. Asia-Pacific Journal on Human Rights and the Law. Jan 1;12(1):5680. 
Deininger K, Squire L.( 1996) A new data set measuring income inequality. The World Bank Economic Review. Sep 1;10(3):565-91.

Hussain M. (2015) Drug Technical Advisory Board recommends faster introduction of newly discovered drugs in India. The National medical journal of India. May 1;28(3):166-.

Jayaraman K, Anitha V, Sivaram M. (2008) Forestry Sector Analysis for the State of Kerala. KFRI Research Report; Jul.

Marmor A. The pure theory of law.

Pinto EP. (2021) An Overview of Health Care Jurisprudence in India. Health Justice in India.:83-
176.

Remya V, Thomas A, Induchoodan D. (2020) Manufacture of Ayurvedic Medicines-Regulatory Aspects. Ayurveda in The New Millennium: Emerging Roles and Future Challenges. Nov 11:21.

Sripati V, Thiruvengadam AK. (2004) India: Constitutional amendment making the right to education a Fundamental Right. International Journal of Constitutional Law Jan $1 ; 2(1): 148-58$.

Tripathi M, Khanna SK, Das M. (2007) Surveillance on use of synthetic colours in eatables vis a vis Prevention of Food Adulteration Act of India. Food Control Mar $1 ; 18(3): 211-9$. 